\title{
Cracking the Code (Meshing and Switching): Standard English as a Required Ticket to Influence
}

\author{
Paul A. J. Beehler
}

\begin{abstract}
Scholarly debates about Standard English in the 1970's were, in part, instigated by the 1969 Task Force on Racism and Bias in the Teaching of English. Committees like this one charged by the National Council of Teachers of English (NCTE) gave rise to such scholars as Rodolfo Jacobson, Patricia Cunningham, and James Sledd - all of whom considered the role of Standard English in classrooms and possible consequences of white supremacy tethered to Standard English. The debate over Standard English and its position in composition classes has evolved over the decades since the 1970's, but the anxiety associated with Standard English has never been extinguished or even fully addressed. Recently, the 2019 College Composition and Communication Conference (CCCC) keynote address, delivered by Dr. Asao B. Inoue, served as a call to action wherein Dr. Inoue encouraged colleagues throughout rhetoric and composition to abandon Standard English. This response considers an excerpt of Dr. Inoue's speech and then ultimately refutes the argument that Standard English should be abandoned. Indeed, such a practice could very well harm first and second generation students, effectively isolating and marginalizing the most vulnerable groups in American universities. Standard English has played an historically seminal role in American universities and broader society, and that role - academically, economically, and socially - continues to reinforce the underpinnings of accurate communication in current American and international communities.
\end{abstract}

Index Terms-Standard English, defense, rhetoric, composition, code-meshing, code-switching.

\section{Introduction: A CONSIDERATION OF MUltiPle ENGLISHES}

The Old Testament of the Bible addresses language as early as Genesis through the story of "The Tower of Babel." In this archetypal story, people are remarkably productive and industrious specifically because of their reliance on a common language. Their ability to advance society first inspires in God a sense of curiosity and, subsequently, alarm. The divine, in Genesis, reveals a provocative reaction, one that decisively and swiftly moves to disrupt society and progress through the destabilization of language:

The Lord came down to see the city and the tower that the men had built. Then the Lord said: "If now, while they are one people, all speaking the same language, they have started to do this, nothing will later stop them from doing whatever they presume to do. Let us then go down and there confuse their language, so that one will

Manuscript received September 9, 2019; revised January 21, 2020.

Paul A. J. Beehler is with the University of California Riverside, United States (e-mail: paulb@ucr.edu). not understand what another says."

Genesis 11: $6-7$. [1]

The story is an important one not only because of its ubiquitous influence in western culture, but also because of its powerful invocation of metaphor. This text puts forth a truism: a diverse people united by a common tongue become formidable even in the eyes of the divine. Indeed, nothing can seemingly stop people from "doing whatever they presume to do" given, specifically, the right linguistic conditions of working within a common language. Language, it would seem, binds all. Alternatively, and proceeding from the same logic, confusing language -- so as to confuse understanding -- consequently deprives people from doing whatever they presume to do. Genesis through the metaphor of the Tower of Babel provides a stark admonishment about a disruption through disunity that can occur when language is fractured, and the divine appears to seize on this weakness in a successful attempt to eradicate competition and even perceived threats. Ultimately, this foundational metaphor impresses upon the reader how fundamentally powerful and transformative a common language is.

The metaphor can be surprisingly useful when thinking about some of the current criticism in Composition/Rhetoric that addresses the linguistic construct of multiple Englishes and their relationship to Standard English, most especially as the relationship is conceived in American higher education. ${ }^{1}$ Historically, the debate about Standard English and its relationship to racism is not a new one; indeed, the arguments have routinely been presented in different registers since the mid-twentieth century, but the positions generally remain the same. Is Standard English racist? Oppressive? The competing position situates Standard English as liberating, even empowering. Geneva Smitherman in talkin that talk: Language, Culture, and Education in African America reflects on how these arguments about the problematic role of Standard English energetically manifested themselves in academia during the 1960 s and 1970 s, noting in particular that "In point of fact, it was argued that Black English is just as linguistically and functionally systematic as white English. However, the 'problem' is that Black English is socially and

\footnotetext{
${ }^{1}$ As L. Milroy points out, "standardization is best treated as a process, since attempts to locate a specific standard (product) are doomed to failure, given that all languages (except dead languages) vary and are in a constant state of change, phonology being particularly resistant to standardization" (173) [2]. This paper is not an attempt to define the process of Standard English or even to define Standard English itself. Rather, the argument here is that those elements that are broadly accepted and codified as Standard English in handbooks like William Strunk and E.B. White's Elements of Style, should be privileged as much as possible in any given college composition classroom.
} 
economically inadequate." $(77-78)^{2}$ [3]. The argument about Standard English and its cultural complexities as it applies to Black English, and, more broadly, to multiple Englishes waxes and wanes over the years, but threads of the argument clearly have continued into the twenty-first century, even enjoying a moment of acute visibility such as when Asao B. Inoue delivered his keynote address to the Conference on College Composition and Communication in March of 2019. Inoue's speech invited professionals in composition to, again, consider the role of Standard English in education, thereby reviving the old debate.

Theoretically speaking, a common, or standard, language can be the gateway through which all individuals can fully participate in society because participation occurs through the nexus of a common language, whatever that language may be, as Smitherman noted in her reflection of the 1960s and 1970s debates. An adopted common language as expressed through phonology, grammar, syntax, and morphology benefits both the individual in terms of economic advancement but also society more broadly because a diversity of thought and skill can be fully incorporated into the fabric of society and then exploited to benefit society as a whole. Some scholars have raised reasonable concerns about the problems that can occur in a classroom that dilutes the educational experience of Standard English through social justice curricula. Marilyn Cochran-Smith et al., for example, are quick to point out that "teacher education for justice centers on kids feeling good and teachers being politically correct, while nobody pays attention to learning" (625) [5]. Most teachers will, at the very least, recognize that standards and rigor in education are important components of the educational process; however, the dilution of the classroom that Cochran-Smith discusses poses a threat to the transmission and implementation of Standard English, a pedagogy that can rely upon highly focused lesson plans that are at least partially grounded in grammar and syntax. If Cochran-Smith et al. are correct, then instructors might be inclined to traverse the slippery slope of validating code-meshing, an approach that invalidates the concept of Standard English, and, arguably, generates confusion about the role of Standard English and expectations around Standard English. Even champions of code-meshing, like John Vance, recognize the inescapable complications language: "If we rely on the meshing of different languages and dialects in our daily discursive practices, and if, moreover, the languages on which we rely are themselves amalgamations of other languages and dialects, then how can we appropriately affix labels to the codes we use, much less map the dynamics of our 'meshing' them?" (281) [6]. To deepen the point, one might ask not only

\footnotetext{
${ }^{2}$ Rodolfo Jacobson in his 1971 article "Cultural Linguistic Pluralism and the Problem of Motivation" lends insight into the early incarnations of this argument that has yet to be resolved: "The knowledge of Standard English is necessary to function successfully in our society; and if Standard English is freed from its unjustified association with 'Anglo speech' and 'white man's talk' and is merely considered a standardized tool of communication, no harm can possibly be inflicted to the learner's self-image nor can its enforcement be considered a construct of white racism." (265) [4]. In some ways, the positions adopted on either side of the debate seem to have calcified over the years, lending themselves to a certain kind of intractability in the argument.
}

how labels and identifications of codes can be established but how syntax and grammar, even in its basic construction, can be identified and applied to language.

The potential pitfall of code-meshing and the subtle displacement of Standard English rests in a slippery slope as it can apply to instruction in the composition classroom; further, code-meshing can result in a dilution of clarity around language because students are tasked with a very complex expectation of mastering not just a single standard but multiple standards for multiple Englishes. Given the limitations of any classroom in terms of time and resources not to mention taxing intellectual faculties, instruction will naturally be strained under such circumstances. One example of the problems that can arise with a diluted approach towards Standard English is evident in the Common Core College and Career Readiness (CCR) Anchor Standards for Reading, Writing, Speaking, and Listening, and Language. The CCR explicitly acknowledges that students should demonstrate proficiency in Standard English, but even champions of the social justice curriculum, like Alison G. Dover, reluctantly recognize from an analysis of their data that "Although submitted lessons placed greater emphasis overall on students' reading, writing, and communication skills than on direct instruction related to Standard English and conventions, half of the participants submitted units that explicitly addressed content and skills found in the CCR Standards for Language" (524) [7]. ${ }^{3}$ In other words, Dover reasonably concedes that any classroom will be limited in terms of scope; further, those classes that support a social justice curriculum will, in all likelihood, displace "direct instruction related to Standard English and conventions" with "students' reading, writing, and communication skills" that rest presumably outside of the direct application of Standard English. Such a pedagogical approach will likely succumb to Cochran-Smith's criticism and John Vance's concession in that the students will have their own understanding of English - that is an English that does not adhere to Standard English - reinforced at the expense of instruction in standard grammar and syntax.

\section{LINGUISTIC CONTEXT FOR STANDARD ENGLISH}

In no way should the exclusivity of Standardized English in the composition classroom suggest an absolute exclusivity of other forms of English, and this point is an important one that deserves to be underscored. Recent scholarship has identified and clarified how code-meshing (Wheeler \& Swords, 2006) operates: students may move between languages and dialects depending on the context and situation [8]. While some scholars (Young \& Martinez, 2011) have argued that code-meshing has inherent challenges, the application of code-meshing presents an exciting linguistic dynamic [9]. To this point, other languages and hybridized languages most certainly have a vital place and function in society, and these languages are, arguably, vital for diversity of thought,

\footnotetext{
${ }^{3}$ Dover asserts her position about the primacy of social justice ideology in education when she argues "Justice-oriented teachers use a curriculum that reflects students' personal and cultural identities; includes explicit instruction about oppression, prejudice, and inequity; and makes connections between curricular standards and social justice topics" (518).
} 
linguistic evolution, and advancement of culture itself; however, even in light of these benefits, an argument can be made that Standard English provides a common stage for all to engage fully in the many diverse endeavors of American society, and, potentially, other societies. In other words, Standard English provides a platform for inclusivity that is arguably absent in multiple Englishes. The common platform that is so crucial to lucid communication requires the attention of all students in an instructional arena, and that level of focus cannot suffer distraction or dilution if students are to have the best opportunity possible to master Standard English. In response to questions about audience and the subject in a composition classroom, John Vance sees inherent value in code-meshing and the polysemous nature of language: "it seems useful to ask them [students] to not only mesh codes, but to consider the politically-charged origins of the 'codes' they employ, and to think about ways in which they might interrogate - and even construct - these codes in terms of their specific personal, cultural, and rhetorical situations" (283). Admittedly, this kind of inquiry and approach can be helpful in the realm of the personal as Vance points out, but such code-meshing in the formal classroom itself will likely dilute the efforts to provide clear and intense instruction around Standard English. The result, then, is to diminish the likelihood that students will develop a linguistic competence based on Standard English.

Pressing this point even further, code-meshing as delineated by Michael-Luna and Canagarajah (2007) and Young et al. (2014) is far more problematic to the process of acquiring and refining Standard English because of the intertwining nature of multiple Englishes, a practice that can directly resist the concept of establishing, as best as possible, a consistent and formal Standard English [10], [11]. Ultimately, composition classes are limited in scope, so instructors must make practical decisions about what will be emphasized and what will be ignored. Displacing instructional time to accommodate code-meshing and code-switching has the unfortunate byproduct of limiting instruction in Standard English and introducing linguistic concepts that actually interfere with Standard English acquisition. As a result, students may be placed at a disadvantage in acquiring the linguistic skills necessary to join in the Burkean parlor.

Many critics, of course, do not accept the premise that Standard English is benevolent to individuals and society, hence the rise of and subsequent defense of code-switching and code-meshing. Some view Standard English as purely a colonial expression, one that is steeped in white supremacy and must be dismantled. Other critics advance the argument further by suggesting Standard English is tantamount to linguistic violence. Melinda J. McBee Orzulak, for example, supports the idea that Deficit Language Ideologies - the idea that Englishes that diverge from Standard English "marginalize nondominant groups and promote dominant groups' interests" (180), presumably both within the confines of education and in society at large [12]. Embracing a pedagogical approach that places Standard English in a seminal position in the composition classroom, according to Orzulak, would
Further advocate for linguistic separatism by ignoring the realities of code-meshing. One aspect of deficit language ideology is the belief that if something is not "standard" English, it is not grammatical or that sloppy people use sloppy grammar. (180)

Whether or not code-meshing reflects how "sloppy people use sloppy grammar" - a concern that seems to be outside the scope of the arguments at hand - greater society almost certainly will equate "sloppy grammar" with deficiencies in education, and this stigma is certainly one students would be motivated to avoid for practical reasons like job opportunities and access to graduate programs.

Sometimes, the perceived linguistic violence associated with Standard English is articulated through concerns about testing. For example, "Language-Based Differences in the Literacy Performance of Bidialectal Youth" by Patriann Smith et al., concludes on the basis of their study on Carribean youth and non-native speakers that the findings serve "to justify the need for closer attention to the pervasive role of colonialism in the dominance of standard English in multilingual testing (Shohamy, 2006)" (1)[13]. The authors suggest that the test of Standard English be modified to account for multiple Englishes: the study "requires that assumptions steeped in colonialism that underlie Standard English literacy testing on the PISA international measure be revisited if bidialectical adolescent learners are to be accurately represented on these measures in much the same manner as their monolingual and Standard English speaking counterparts" (1). In short, the authors advocate for testing vehicles to consider factors outside of Standard English to accurately represent achievement in the English language, a position that, on its face, seems inherently contradictory. That alteration, as is argued here, would result in the institutionalization and reinforcement of multiple Englishes or a linguistic pivot to non-standard English. Testing vehicles, of course, can have a profound effect on pedagogy, praxis, and curriculum. Smith is one of the more recent scholars to forward such a particularly lucid example of the antagonism towards Standard English, but Smith's argument is notable and potent because the authors suggest changes to the mechanism of testing. ${ }^{4}$

Under no circumstances am I casting aspersions through this argument on the scholars or research conducted around the colonial aspect of teaching Standardized English; however, reconciling the suggestion to dilute Standardized English with other dialects does seem to stand in opposition to some of the principal skill sets employers seek. In the "Report of The National Commission on Writing for America's Families, Schools, and Colleges" generated by College Board in September of 2004, writing was recognized as a "'threshold skill' for both employment and promotion, particularly salaried employees." (3) [14]. The survey considered 120 major American corporations that represented almost eight million workers. The term "writing"

\footnotetext{
${ }^{4}$ There is a veritable cavalcade of scholars who attack standard English. Consider Andrea Sturzuk's "'The Standard Remains the Same': Language Standardization, Race, and Othering in Higher Education" (2015) or the recent research of Canagarajah (2006a), Canagarajah (2006b), Shohamy (2006). Earlier impulses in such scholarship can be found in the work of Sandra Anderson Garcia's "Colonialism in the Classroom: Teaching 'Good' Grammar to Black Children.”
} 
was used synonymously with Standard English in that writing secured the individual with an opportunity "to present one's thoughts coherently, cogently, and persuasively on paper." (5). Clear and universal communication on paper, then, required the adept use of a common language - Standard English.

To be absolutely direct, Standard English is essential for accurate communication precisely because it minimizes difference in linguistic terms, and, as the College Board report suggests, it is a skill that is highly sought after in the marketplace. ${ }^{5}$ The practical value of Standard English has also been recognized time and time again in American higher education. The most prestigious of the American public institutions of higher education, the University of California, has placed a premium on strong composition skills from very early on in its history, and the proficiency of students to write effectively has been judged entirely on the principles of Standard English. Indeed, Professor Cornelius Beech Bradley in 1883 began the process of enforcing codified standards in English composition at the University of California:

From the very beginning of his tenure at the university, Bradley pursued a career in composition enforcement. His job as a parsekeeper is glaringly apparent in his diary entry concerning the administration of entrance examinations for the 1883-84 academic year: "Fifteen students fail the entrance examination in Subjects 1 and 14."

\section{Stanley 30 [15]}

Subject one was the designation for English composition and subject fourteen was the designation for English literature. This very early inception of an entrance exam eventually, in 1898, was institutionalized as the Subject A and continued in an uninterrupted capacity that gave birth to a system-wide placement exam in 1986, one dedicated to the principles of Standard English. That Subject A exam operated until the early twenty-first century when the nomenclature changed to the Analytical Writing Placement Exam (AWPE). Particularly important to note is that the standards and expectations have not changed throughout this robust one hundred and twenty-six-year history, though the exam itself has evolved over several iterations. The concern about Standard English proficiency is also evident in other standardized national entrance tests like the S.A.T. and A.C.T., both of which have full sections dedicated to critical reading and Standard English error recognition. These admissions tests rely not only on multiple choice questions, but also an optional free response essay. Both at the state and national level in America, then, Standard English holds a prominent position.

Why has there been such a stalwart commitment to Standard English in the flagship of American public universities, and, indeed, secondary schools across America that harken back to the nineteenth century? The traditional response is remarkably pragmatic: Students with such skills are far more likely to excel in courses that use Standard

\footnotetext{
${ }^{5}$ One need look no further than Ferdinand de Saussure's famous tex Course in General Linguistics and the poignant concept of sign and signifier. The greater the linguistic difference between sign and signifier leads to the greater the possibility of slippage between sign and signifier.
}

English textbooks, rely on lectures in English, and routinely assign papers to be submitted in English.

Very recently, though, some scholars have resurrected arguments rooted in the 1970's. These arguments question the established practice of supporting Standard Language Ideologies, and perhaps the most direct and visible opposition to embracing Standard English of late has emerged from Dr. Asao B. Inoue, the past President of the Conference on College Communication and Composition (CCCC) and keynote speaker at the 2019 CCCC. As a part of the National Council of Teachers of English and The American Council of Learned Societies, the CCCC and its positions deserve careful consideration from rhetoricians of all ilk in the field. Certainly, all scholars should read the full text of Dr. Inoue's speech, "How Do We Language So People Stop Killing Each Other, or, What Do We Do about White Language Supremacy?," which can be found at https://docs.google.com/document/d/11ACklcUmqGvTzCM PlETChBwS-Ic3t2BOLi13u8IUEp4/mobilebasic. Though admittedly out of context, some poignant statements from the speech can help form an impression about how the field currently approaches, interprets, and contextualizes Standard English. To be fair, a full and close reading of Inoue's address, something not possible to achieve in this brief essay, is necessary to understand some of the general positions the leadership of the CCCC adopted.

\section{ABbREVIATED Position OF THE CCCC LEADERSHIP}

Dr. Inoue's argument, in many ways, can be distilled to a paragraph found about almost a third of the way through the speech, and it reads as follows:

Again, let me compassionately urge you to sit in discomfort: If you use a single standard to grade your students' languaging, you engage in racism. You actively promote White language supremacy, which is the handmaiden to White bias in the world, the kind that kills Black men on the streets by the hands of the police through profiling and good ol' fashion prejudice. Inoue 4 [16]

A "single standard" as Dr. Inoue identifies in this reflection is most readily understood as a recognized, standardized English. Dr. Inoue is dedicated to, as I hope most academics are, a diminishment of racism. In his zeal to achieve such a noble goal, however, he has created an artificial dichotomy that, if considered in all of its subtleties, might inadvertently advance racism not in a theoretical manner, as Dr. Inoue frets over, but in a pedagogical manner that has real world consequences. His argument, stated directly in this passage, suggests that a single standard to grade student work is tantamount to racism and simultaneously promoting "White language supremacy, which is the handmaiden to White bias in the world." If a single standard - whatever that standard may be - is not applied to all students equally, then it seems that Dr. Inoue is suggesting that multiple standards be applied to students. That way madness lies; let us shun that. Such an approach would encourage instructors to grade writing based on different standards for different students. Can one fathom a better approach to insure and embed racism in a powerfully 
seductive realm? The classroom under such a pedagogy would almost certainly encourage instructors to reward different forms of English, and, of course, instructors would have to make decisions riddled with subjectivity and bias. For example, what constitutes an "A" paper in a southern non-standardized English dialect? What constitutes a "C" paper in a dialect of English found in a specific ethnic population? How many types of English can be documented? What counts as a type of English? Does such a type of English infer its own standardization?

Standardized English as we know it evolves at a glacial pace, but the point is that it does evolve. The language incorporates experience and culture as the years pass, and through that slow but inclusive process, the language is constantly subjected to linguistic pressures that shape the language in such a way as to reflect societal structure, culture, and dynamics. The consequence of such a living linguistic medium embodied in Standard English is that the formal rules and applied standard of the language is, by necessity, very slow to follow the living, dynamic, spoken language. Such a deliberative system, then, is inherently unfamiliar to all students who approach the language. Some students, of course, will be closer to standardized English because of their backgrounds while other students may find themselves further from the confines of standardized English. The position of inclusion articulated here contrasts rather starkly with some scholars in the field like Bethany Davila, who expresses concern about what she interprets as inherently exclusive properties of Standard American Edited English (SAEA):

All groups stand to benefit from using the standard language variety, and no group has more access than any other to the standard language. This positioning hides standard languages'

role in hegemony: The common understandings of and about SEAE not only benefit those how have power but also shield those in power - as well as SEAE - from critique.

129 [17]

Standardized communication will likely benefit all practitioners; however, all groups struggle to attain competencies in SAEA because it is a dialect separate from all others. Clearly some students will have a closer connection to SAEA based on past education and culture, but no student lives in an SAEA bubble that perfectly reflects SAEA. To that extent, all students must struggle with SAEA. Through the acquisition and full appropriation of SAEA, though, a universal linguistic platform can be exploited for accurate and coherent articulation of thought. This goal is essential for effective communication, and effective communication is a necessary component to facilitating peace, understanding, trust, and cooperation. Further, such qualities play a seminal role in understanding the common human experience. On a more practical level, such qualities can improve human lives wholesale through the exchange of ideas, advancement of thought, and facilitation of trade.

\section{PRACTICAL CONSIDERATIONS}

Trade is a particularly powerful activity, one that is not lost on students and rightfully so. The Cooperative Institutional Research Program has run a survey of college freshman over the past forty years, and the results of the recent 2014 survey are compelling. When asked why they would like to attend college, students identified the single most important reason, as noted by $86.1 \%$ of the responses, "To be able to get a better job" (Rampell 2) [18]. That statistic is striking and should give all educators pause. American students spend exorbitant amounts of money on their tertiary education, and many have no choice but to assume heavy debt loads to finance their educations. According to 2015-2016 data harvested by the United States Department of Education, forty-seven percent of all students at four year colleges during the period in question accepted annual student loans for an average of $\$ 7600$ per student (Institute of Education Sciences, 6-8) [19]. If students graduated in five years under these conditions, almost half of all students would shoulder a debt load of $\$ 38,000$.

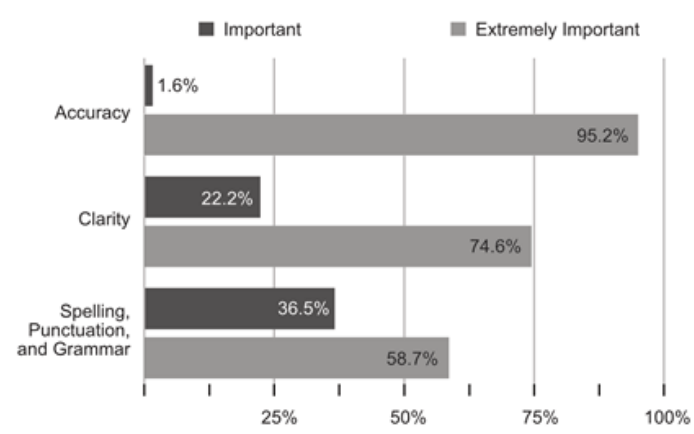

Fig. 1. What do employers value in writing?

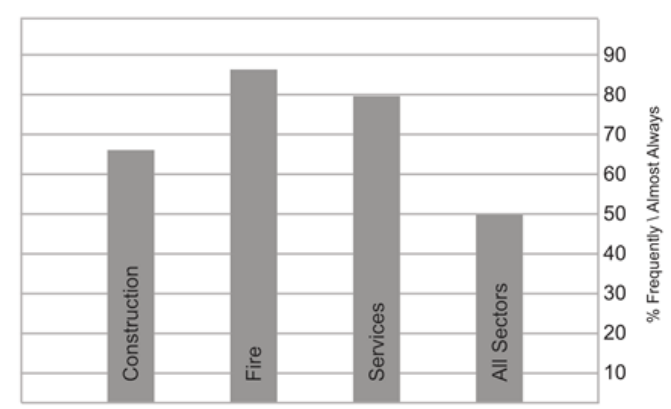

Fig. 2. Who considers writing when hiring salaried employees?

\section{CONCLUSION}

Ultimately, institutions of higher learning should not be dismissive of students' desires and needs. After all, students elect to attend a university, hopefully, to be exposed to new ideas. They also, however, face real world concerns about paying for their education, and the responsible position is to help prepare students for employment that will help retire their debt. Fig. 1 and Fig. 2 respectively demonstrate not only the seminal role Standard English plays in the form of writing through accuracy, clarity, and grammar, but also the importance writing holds in the hiring process itself. If this very important concern for students is not addressed, then universities will be in the business of absorbing student resources while simultaneously chaining students to debt. For those students from lower socio-economic groups, this arrangement is very bad indeed. If colonialism is the exploitation of resources and loss of influence in a social 
system, then is not the act of refusing instruction in standardized English a practical act of colonialism? And does it not then have real world consequences?

To foster the most fluid and accurate exchange of ideas, a process that grants participants access to economic and social power, depends to an extent on a standard language. Social circumstances over the last several hundred years, for good or ill, have led the international community to the acceptance of English as that standard language. As educators, we will greatly advance our students if we provide intense instruction in Standard English. Alternatively, those well intentioned teachers who choose to withhold such instruction for whatever reason will likely disadvantage their students and visit real-world harm to satisfy an impulse that very well may involve egocentric virtue signaling.

\section{CONFLICT OF INTEREST}

The author declares no conflict of interest.

\section{AUTHOR CONTRIBUTIONS}

Paul AJ Beehler conducted the research of secondary sources, crafted the argument, and wrote the paper. The sole author also reviewed the final draft of the manuscript.

\section{REFERENCES}

[1] New American Bible, New York, NY: Catholic Book Publishing Company, 1970, pp. 6-7.

[2] L. Milroy, "Standard English and language ideology in Britain and the United States" Standard English: The Widening Debate, London, UK: Routledge, 1999, pp. 173-206.

[3] G. Smitherman, Talkin That Talk: Language, Culture, and Education in African America, London: Routledge, 2000, pp. 77-78.

[4] R. Jacobson, "Cultural linguistic pluralism and the problem of motivation," TESOL Quarterly, vol. 5, no. 4, pp. 265-284, 1971.

[5] M. Cochran-Smith, J. Barnatt, R. Lahann, K. Shakman, and D. Terrell, "Teacher education for social justice: Critiquing the critiques," Handbook of Social Justice in Education, New York, NY: Routledge, 2009, pp. 625-640.

[6] J. Vance, "Code-meshing meshed codes: Some complications and possibilities," Journal of Academic Composition-Ames, vol. 29, no. 1/2, pp. 281-284, 2009.

[7] A. Dover, "Teaching for social justice and the common core: Justice-oriented curriculum for language arts and literacy," Journal of Adolescent \& Adult Literacy, vol. 59, no. 5, pp. 517-527, 2015.

[8] R. Wheeler and R. Swords, Code-Switching: Teaching Standard English in Urban Classrooms, Urbana: National Council of Teachers, 2006.

[9] V. Young and A. Martinez, Code-Meshing as World English: Pedagogy, Policy, Performance, Urbana: National Council of Teachers of English, 2011.

[10] S. Michael-Luna and A. Canagarajah, "Multilingual academic literacies: Pedagogical foundations for code meshing in primary and higher education," Journal of Applied Linguistics, vol. 4, no. 1, pp. 55-77, 2007.

[11] V. Young, R. Barrett, Y. Young-Rivera, and K. Lovejoy, Other People's English: Code-Meshing, Code-Switching, and African American Literacy, New York: Teachers College Press, 2014.

[12] M. M. Bee Orzulak, "Disinviting deficit ideologies: Beyond 'that's standard,' 'that's racist,' and 'that's your mother tongue,"' Research in the Teaching of English, vol. 50, no. 2, pp. 176-198, 2015.
[13] P. Smith, J. Cheema, A. Kumi-Yeboah, J. Warrican, and M. Alleyne, "Language-based differences in the literacy performance of bidialectal youth," Teachers College Record, vol. 120, no. 1, p. 1, 2018.

[14] Report of The National Commission on Writing for America's Families, Schools, and Colleges, College Entrance Examination Board, p. 3, 2004.

[15] J. Stanley, The Rhetoric of Remediation, Pittsburgh, PA: University of Pittsburgh Press, 2010, ch. 2, p. 30.

[16] A. Inoue, "How do we language so people stop killing each other, or, what do we do about white language supremacy?" presented at the Conference on College Composition and Communication, Pittsburgh. March 13-16, 2019.

[17] B. Davila, "The inevitability of 'standard' English: Discursive constructions of standard language ideologies," Written Communication, vol. 32, no. 2, pp. 127-148, 2016.

[18] C. Rampell, "Why do Americans go to college? First and foremost, they want better jobs," The Washington Post, The Washington Post: Democracy in Darkness, 2015.

[19] United States, Department of Education National Center for Education Statistics, 2015-2016 National Postsecondary Student Aid Study, Institute of Education Sciences, Washington, US Department of Education, January 2018

Copyright $\odot 2020$ by the authors. This is an open access article distributed under the Creative Commons Attribution License which permits unrestricted use, distribution, and reproduction in any medium, provided the original work is properly cited (CC BY 4.0).

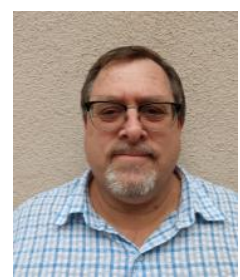

Paul A. J. Beehler was born in California, where he was raised, pursuing his education through the public school system. He received a B.A. in English literature from the University of California, Los Angeles (1991); an M.A. in English literature with an emphasis in Shakespeare and Victorian literature from California State University, East Bay in Hayward, California (1994); and a Ph.D. from the University of California, Riverside (2000) with a doctorate dedicated to the concept of religious disruption in William Shakespeare's drama.

He currently serves as an associate professor of teaching in the Department of English at the University of California, Riverside in Riverside, California, and he is the director of the English Language Writing Requirement (ELWR) Prior to this position, he was a lecturer in the University Writing Program and the School of Business at U.C. Riverside. He also served as a lecturer in the Department of English at California State University, Hayward. He has authored over a dozen articles including "Change and Sexuality: Ursula and Ariel as Markers of Metamorphosis in The Little Mermaid" (Write It, Sixth Edition, Dubuque, Iowa: Kendall Hunt, 2017), "Training International Teaching Assistants Through a Writing Across the Curriculum Course" (Hamden, Connecticut; College of Arts and Sciences at Quinnipiac University, 2016), and "Macduff's Amorphous Identity: Equivocation and Uncertainty as Defining Markers in Shakespeare's Macbeth" (Copiapo, Chile: Universidad de Atacama, 2009). Another article, "Historical Nexus: Bewitching Nurses in Rupert Goold's Visual Medium of Macbeth" is due out in The Southern African Journal of Medieval and Renaissance Studies in late 2019. His current research interests are Shakespeare, composition theory, and writing program administration.

Professor Beehler is a member of the National Council of Teachers of English (NCTE), College Composition and Communication (CCC), and the National Association of Scholars (NAS). Currently, he serves as ex officio on the Committee on Prepatory Education at the University of California, Riverside and is the Chair of the UC systemwide committee on English for Multilingual Students. Professor Beehler is also the co-founder of the Writing And Foster Youth Alliance (WAFYA) and holds the position of co-editor for the Instructor's Manual of Write It.

Married to his wife Dorene for over twenty years, Paul has two children, Paul (Harry) and Megan. 